\title{
BMJ Open A cross-sectional survey investigating the desensitisation of graphic health warning labels and their impact on smokers, non-smokers and patients with COPD in a London cohort
}

\author{
Culadeeban Ratneswaran, ${ }^{1}$ Ben Chisnall, ${ }^{2}$ Panagis Drakatos, ${ }^{1}$ \\ Sukhanthan Sivakumar, ${ }^{2}$ Bairavie Sivakumar, ${ }^{2}$ Miriam Barrecheguren, ${ }^{1}$ \\ Abdel Douiri, ${ }^{3}$ Joerg Steier ${ }^{1,2}$
}

To cite: Ratneswaran $\mathrm{C}$, Chisnall B, Drakatos $\mathrm{P}$, et al. A cross-sectional survey investigating the desensitisation of graphic health warning labels and their impact on smokers, non-smokers and patients with COPD in a London cohort. BMJ Open 2014;4: e004782. doi:10.1136/ bmjopen-2013-004782

- Prepublication history and additional material is available. To view these files please visit the journal (http://dx.doi.org/10.1136/ bmjopen-2013-004782).

Received 31 December 2013 Revised 7 May 2014 Accepted 9 May 2014

CrossMark

For numbered affiliations see end of article.

Correspondence to Dr Culadeeban Ratneswaran; c.ratneswaran@gmail.com

\section{ABSTRACT}

Objectives: There is a lack of evidence regarding the effectiveness of graphic health warning labels (GHWL) in different individuals, including patients with chronic obstructive pulmonary disease (COPD). Investigating knowledge and attitudes may allow better implementation of future public health policies. We hypothesised that differences in the impact of GHWL exist between non-smokers, smokers and patients with COPD, with decreased efficacy in those groups who are longer and more frequently exposed to them.

Participants and setting: 163 participants (54\% male, aged 21-80) including 60 non-smokers, 53 smokers and 50 patients with COPD (Gold stage II-IV), attending London respiratory outpatient clinics, participated in case-controlled surveys (50 items).

Outcome measures: Ten different GHWL were shown and demographics, smoking history, plans to quit, smoking-risk awareness, emotional response, processing and impact of GHWL on behaviour were recorded. Patients were further asked to prioritise the hypothetical treatment or prevention of five specific smoking-related diseases.

Results: Smokers, in particular those with COPD, were less susceptible to GHWL than non-smokers; $53.4 \%$ of all participants expressed fear when looking at GHWL, non-smokers $(71.9 \%)$ more so than smokers $(39.8 \%$, $p<0.001)$. COPD participants were less aware of the consequences than non-COPD participants $(p<0.001)$, including an awareness of lung cancer $(p=0.001)$. Lung cancer (95\%), oral cancer $(90.2 \%)$, heart disease $(84.7 \%)$ and stroke $(71.2 \%)$ were correctly associated with smoking, whereas blindness was least associated $(23.9 \%)$. However, blindness was prioritised over oral cancer, stroke and in patients with COPD also over heart disease when participants were asked about

hypothetical treatment or prevention.

Conclusions: GHWL are most effective in nonsmokers and a desensitisation effect was observed in smokers and patients with COPD. As a consequence, a tailored and concerted public health approach to use such messages is required and 'blindness' deserves

\section{Strengths and limitations of this study}

Detailed assessments used structured surveys, which were designed following an internal peerreview process among three tertiary teaching hospitals and one academic institution.

- Patients with chronic obstructive pulmonary disease (COPD) were more reluctant to take part in the research and a more substantial aversion to graphic health warning labels may have been masked in this group. Further, the COPD cohort was older and had more male participants than the other groups.

- Data were collected directly from patient groups in an outpatient setting, and therefore generalisability to the wider population may be limited.

to be mentioned in this context because of an unexpectedly high-deterring impact.

\section{INTRODUCTION}

Tobacco use is one of four factors responsible for the majority of all worldwide deaths caused by non-communicable disease, according to the WHO. ${ }^{1}$ It causes lung cancer and chronic obstructive pulmonary disease (COPD). ${ }^{2}{ }^{3}$ Smoking cessation at any stage improves health outcomes, even in patients with advanced $\mathrm{COPD}^{4}$ and, although it is difficult to change smoking behaviour, public health campaigns featuring primary and secondary prevention influence smoking habits and public health in the long term. ${ }^{5}$

Graphic health warning labels (GHWL) have been used over several years to promote smoking cessation and increase awareness of smoking-related side effects. ${ }^{6}$ Various studies 
have described their efficacy, which appears to be more effective than text-only labels, ${ }^{7-11}$ but difficulties still persist to encourage smoking cessation. ${ }^{12}$ Despite all efforts and a comprehensive government tobacco plan (box 1), ${ }^{13}$ more than $21 \%$ of the UK population continue to smoke. ${ }^{14}$

\section{Awareness of smoking-related ill health}

Knowledge of smoking-related diseases among smokers and non-smokers, including exposure to second-hand smoke, oral health and various types of cancer, differs significantly, ${ }^{10}{ }^{15}$ even among medical students. ${ }^{16}$ While cardiovascular and respiratory risks are well acknowledged, this is not true for other diseases, particularly for blindness. ${ }^{17-21}$

\section{COPD and GHWL}

Vardavas et $a l^{8}$ investigated the significant role GHWL might play in preventing smoking during early adolescence, a crucial period in which experimentation and addiction commonly occur. ${ }^{22}$ Despite their efficacy, longterm exposure to such warnings may have a desensitising effect on attitudes towards smoking cessation.

Desensitisation to GHWL could have the greatest impact in patients with COPD because they are exposed long-term to the efforts of public health campaigns. Indeed, older smokers are also reported to demonstrate less interest in quitting smoking ${ }^{23}$ and they more often attribute symptoms to the effect of ageing or a nonmedical cause. ${ }^{24}$ A reduced respiratory symptom attribution to smoking would lead to a reduced likelihood to quit. ${ }^{25}$ COPD is also associated with a higher prevalence of depression, poor memory, decreased attention ${ }^{26}$ and mild cognitive impairment. ${ }^{27} 28$ These factors may reduce the cognitive impact GHWL have on smoking cessation and warrant further investigation.

The present study aims to investigate differences in GHWL impact, and knowledge of smoking outcomes in smokers, non-smokers and patients with COPD; we hypothesised a decreased efficacy on individuals with increased exposure to smoking. Identifying individual responses may facilitate a more tailored public health approach for the utilisation of GHWL in future health policies.

\section{Box 1 Government tobacco plan}

The six-part governmental tobacco control plan for England

1. Stopping promotion of tobacco

2. Making tobacco less affordable

3. Effective regulation of tobacco products

4. Helping tobacco users to quit

5. Reducing exposure to second-hand smoke

6. Effective communications for tobacco control

\section{PATIENTS AND METHODS}

The study was approved by the local research ethics committee (reference number 12/NE/0013) and was performed at Guy's \& St Thomas' NHS Foundation Trust, London, UK. Prior to participation, informed and written consent was obtained for all participants. Inclusion criteria were: fluent English, respiratory department outpatients, age 21-80 years, both genders, smokers, non-smokers and ex-smokers, as well as patients with COPD (GOLD stage II-IV) with a prediagnosed condition. Patients who were unable to communicate, understand or view the GHWL or consent form were excluded.

One hundred and sixty-three participants were studied, including 60 non-smokers, 53 smokers and 50 patients with COPD (smokers and non-smokers, see online supplementary tables E1 and E2). A structured survey was designed to investigate the awareness of smoking risks and the effectiveness of GHWL within these groups.

\section{Structured survey}

The survey contained 50 items based on those utilised by previous studies. ${ }^{19} 2029$ These items were included following an internal peer review process among three tertiary teaching hospitals and one academic institution (King's College London, UK; the survey is available in the appendix and more details can be found in the online supplementary materials). The following health risks were included:

1. Mouth and throat cancer

Smoking cessation causes a $50 \%$ reduction in the risk of oral cancer within 5 years. ${ }^{30}$

2. Lung cancer

Approximately $90 \%$ of male lung cancer deaths and $75-80 \%$ of female lung cancer deaths in the USA are caused by smoking each year. ${ }^{31}$

3. Heart disease

Estimations attribute $40 \%$ of heart disease to smoking. ${ }^{32}$

4. Stroke

Smoking could increase the risk of stroke by 2 4-fold. ${ }^{33}$

5. Blindness

Estimations attribute smoking to approximately $20 \%$ of new blindness in people over the age of $50 .{ }^{34}$

Participants were then shown GHWL $(n=10)$ and their responses were recorded. More details about this can be found in the online supplementary material. The surveys were conducted by investigators with a medical background who were instructed to remain neutral and not to influence decision-making. Training took place prior to data collection and at two weekly intervals, lasting 15-20 $\mathrm{min}$, to standardise the interview process and minimise investigator-led bias.

\section{Statistical analysis}

Sample size calculations revealed that at least 50 participants were required in each arm of the study to achieve a 
power of 0.8 (for more details on the sample size calculation, please refer to the online supplementary materials). Data were collected using MS Excel 2007 (Microsoft Corporation, Seattle, Washington, USA); they were analysed using SPSS statistics 21 (IBM, New York, New York, USA) and tested for a normal distribution using the Kolmogorov-Smirnov test. $\chi^{2}$ tests were used to compare categorical data. Non-categorical data were analysed using unpaired $t$ tests, if data were normally distributed, or Mann-Whitney non-parametric tests if they were nonnormally distributed. A regression analysis was conducted, using binary logistic regression and multiple linear regression, and applied to the primary outcome measure of knowledge score (the number of smoking-related risks that each participant was aware of). The independent variables in the analysis were age, gender, sex, ethnicity, smoking status and COPD status. Data are presented as mean (SD), unless otherwise indicated. A level of significance was defined as $\mathrm{p}<0.05$.

\section{RESULTS}

A total of 163 participants $(54 \%$ male $(\mathrm{m})$, age 52.4 (17.8) years) were included, with 60 non-smokers without airway disease $(38.3 \% \mathrm{~m}$; age 41.4 (16.4) years), 53 smokers without airway disease $(69.8 \% \mathrm{~m}$, age 49.7 (13.1) years) and 50 patients with COPD $(56 \% \mathrm{~m}$; age 68.6 (10.7) years); this group contained smokers and non-smokers (please refer to the online supplementary tables E1 and E2). The group with non-smokers had more female participants than the group with smokers and the one with patients with COPD. The COPD group was older than the other two groups. The ethnic background of all participants was predominantly 'White' (79\%), followed by 'Asian/Asian British' (10\%) and 'Black/Black British' (9\%; table 1).

\section{AWARENESS OF HEALTH RISKS ASSOCIATED WITH SMOKING}

In total, $93.3 \%$ of smokers without COPD stated that they had thought about the health risks associated with smoking compared with $75 \%$ of smokers with COPD $(\mathrm{p}=0.097)$. Across all participants, the greatest awareness was of lung cancer $(95.0 \%)$, followed by mouth and throat cancer $(90.2 \%)$, heart disease $(84.7 \%)$ and stroke $(71.2 \%)$. Blindness was least well known (23.9\%).

Non-smokers revealed an increased awareness of associations between smoking and mouth and throat cancer ( $p=0.004)$ compared with smokers (figure 1). Patients with COPD expressed a decreased awareness of lung cancer $(p=0.001)$, heart disease $(p=0.012)$, stroke $(p=0.001)$ and mouth and throat cancer $(p<0.001)$ compared with the other groups (figure 2). There was no significant difference between groups in the awareness of blindness.

\section{Impact of smoking consequences on future behaviour}

Smokers were more motivated to quit smoking if, hypothetically, they were to develop heart disease $(89.7 \%$ vs $75 \%, \mathrm{p}<0.001)$, stroke $(82.8 \%$ vs $75 \%, \mathrm{p}<0.001)$, blindness $(89.7 \%$ vs $66.7 \%, \mathrm{p}<0.001)$, mouth and throat cancer $(93.1 \%$ vs $75 \%, \mathrm{p}<0.001)$ or lung cancer $(89.7 \%$ vs $83.3 \%, \mathrm{p}<0.001)$ when compared to patients with COPD. Non-smokers scored similarly to patients with COPD (9.4 (1.1) vs 8.7 (2.3) points, $\mathrm{p}=0.055)$ when asked about the harmfulness of smoking to health, but they scored higher than current smokers (8.4 (1.5) points, $\mathrm{p}=0.004$; table 2).

When given the choice to avoid one of five hypothetical conditions associated with smoking, smokers rated lung cancer highest, followed by heart disease, blindness, mouth and throat cancer and finally stroke. Similarly, non-smokers ranked lung cancer highest, followed by heart disease, blindness, mouth and throat cancer and stroke. Patients with COPD ranked lung cancer highest, followed by blindness, heart disease, mouth and throat cancer and stroke. However, no significant differences existed between ranks in the different subgroups (table 3 and see online supplementary table E3).

When participants had to choose to hypothetically treat only one of these five smoking-associated conditions, smokers most commonly ranked lung cancer first,

Table 1 Participants' demographics, revealing mean age (with range), number of participants according to gender (\%) and ethnicity $(\%)$ for all groups

\begin{tabular}{|c|c|c|c|c|c|}
\hline & All $(\mathrm{N}=163)$ & $\begin{array}{l}\text { Non-smokers } \\
\text { (non-COPD;N=60) }\end{array}$ & $\begin{array}{l}\text { Smokers } \\
\text { (non-COPD; N=53) }\end{array}$ & $\operatorname{COPD}(\mathrm{N}=50)$ & $\begin{array}{l}\chi^{2} / \text { one-way } \\
\text { ANOVA ( } p \text { value) }\end{array}$ \\
\hline Age in years (range) & $52.4(18-90)$ & $41.4(18-85)$ & $49.7(24-74)$ & $68.6(40-90)$ & $<0.001$ \\
\hline \multicolumn{6}{|l|}{$\operatorname{Sex}(N, \%)$} \\
\hline Male & $88(54 \%)$ & $23(38 \%)$ & $37(70 \%)$ & $28(56 \%)$ & 0.003 \\
\hline Female & 75 (46\%) & 37 (62\%) & $16(30 \%)$ & 22 (44\%) & \\
\hline \multicolumn{6}{|l|}{ Ethnicity/N } \\
\hline White & 129 (79\%) & 43 (72\%) & 41 (77\%) & 45 (90\%) & \\
\hline Asian/Asian British & $17(10 \%)$ & $9(15 \%)$ & $7(13 \%)$ & $1(2 \%)$ & 0.074 \\
\hline Black/Black British & $14(9 \%)$ & $5(8 \%)$ & $5(9 \%)$ & $4(8 \%)$ & \\
\hline Mixed & $3(2 \%)$ & $3(5 \%)$ & $0(0 \%)$ & $0(0 \%)$ & \\
\hline
\end{tabular}


Figure 1 Awareness of smoking-related consequences (smokers vs non-smokers), showing the differences in number of respondents (\%). Significant differences are marked $\left({ }^{* *} p<0.01\right)$.

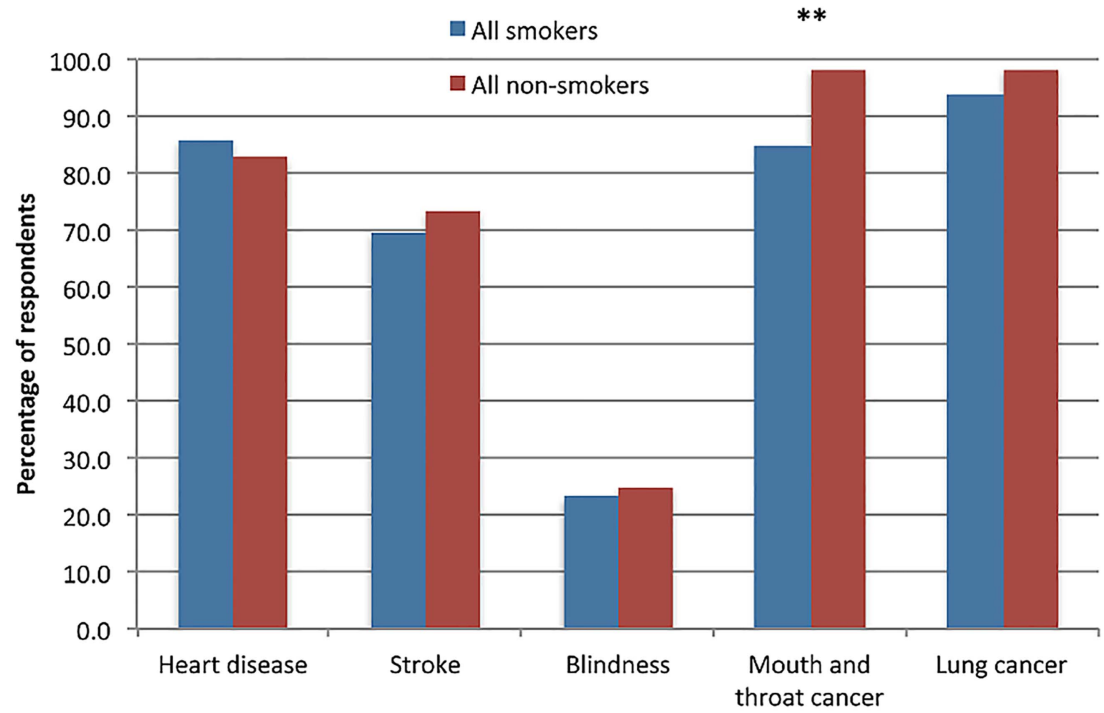

Smoking consequence followed by heart disease, blindness, stroke and lastly mouth and throat cancer. Non-smokers most commonly ranked lung cancer highest, followed by heart disease, blindness, mouth and throat cancer and stroke. Patients with COPD most commonly ranked lung cancer highest, followed by blindness, heart disease, mouth and throat cancer and stroke. Smokers were significantly more likely to seek hypothetical treatment for lung cancer compared with non-smokers $(p=0.005)$ who were more likely to seek treatment for mouth and throat cancer $(\mathrm{p}=0.043$; table 3 and see online supplementary table E4).

\section{Response and processing of GHWL}

Among all participants, $53.4 \%$ of patients experienced fear after viewing pictures of GHWL, $78.5 \%$ of participants expressed disgust and $28.8 \%$ would actively avoid labels if they saw them in public. Smokers experienced less fear when looking at GHWL (71.9\%) compared with non-smokers (39.8\%; $<<0.001$; figure 3). There was no significant difference in avoiding GHWL or feelings of disgust between smokers and non-smokers (table 3). Patients with COPD experienced less fear, disgust and were less likely to avoid looking at GHWL compared with other groups $(\mathrm{p}=0.016$; figure 4$)$, but only avoidance reached the level of statistical significance (table 4).

GHWL would have been more sufficient to prevent or stop smoking in non-smokers than smokers $(\mathrm{p}<0.001)$. Non-smokers were more likely than smokers to think about the warning messages on cigarette packaging $(\mathrm{p}=0.006)$ and talk about the warning labels to others $(\mathrm{p}<0.001$; online supplementary figure E1). Patients with COPD read the packaging less often $(p<0.001)$ and less carefully $(p=0.010)$; they were less likely to think about
Figure 2 Awareness of smoking-related consequences (chronic obstructive pulmonary disease (COPD) vs non-COPD), showing the differences in number of respondents (\%). Significant differences are marked $\left({ }^{*} p<0.05 ;{ }^{* *} p<0.01 ;{ }^{* *} p<0.001\right)$.

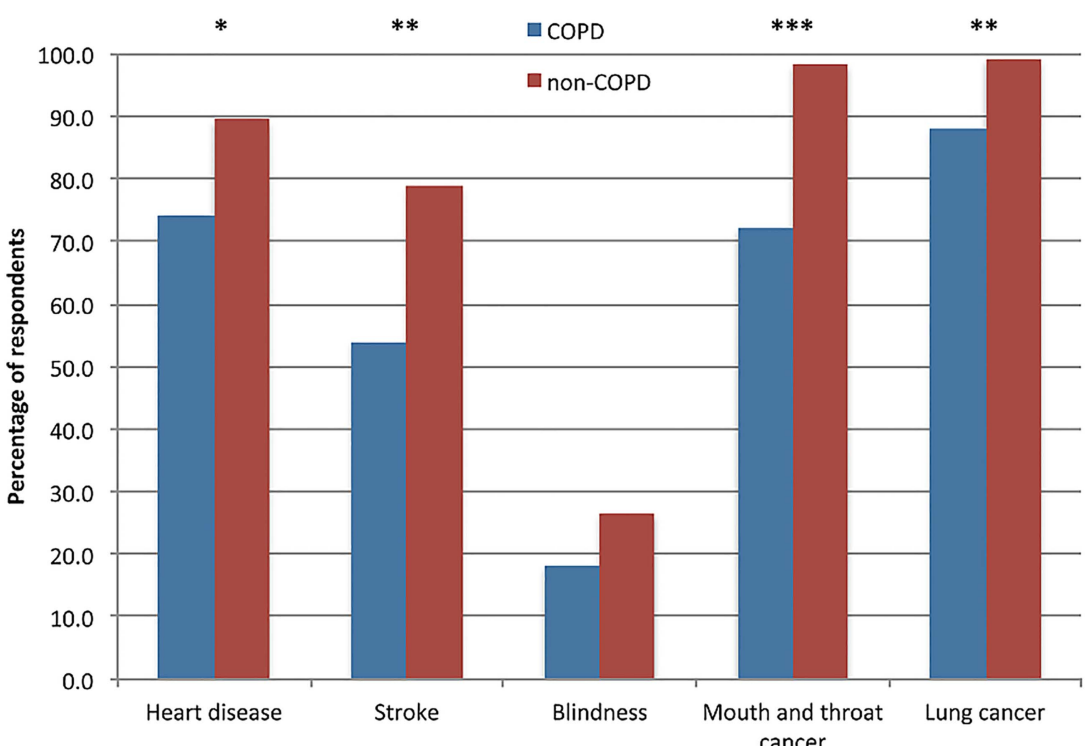

cancer 
Table 2 Awareness of smoking consequences

\begin{tabular}{|c|c|c|c|c|c|c|}
\hline & $\begin{array}{l}\text { COPD } \\
(n=50)\end{array}$ & $\begin{array}{l}\text { Non-COPD } \\
(n=113)\end{array}$ & p Value & $\begin{array}{l}\text { Smokers } \\
(n=99)\end{array}$ & $\begin{array}{l}\text { Non-smokers } \\
(\mathrm{n}=64)\end{array}$ & p Value \\
\hline $\begin{array}{l}\text { (1) How harmful is smoking to health? (non-normal) } \\
\text { mean (SD) }\end{array}$ & $8.7(2.3)$ & $8.9(1.4)$ & 0.564 & $8.4(1.5)$ & $9.4(1.1)$ & 0.004 \\
\hline $\begin{array}{l}\text { Awareness of smoking-related side effects: total score } \\
\text { out of } 5 \text {, mean (SD) }\end{array}$ & $3.1(1.4)$ & $3.9(1.0)$ & $<0.001$ & $3.6(1.2)$ & $3.8(1.1)$ & 0.293 \\
\hline Awareness of heart disease as related to smoking (\%) & 74.0 & 89.4 & 0.012 & 85.9 & 82.8 & 0.598 \\
\hline Awareness of stroke as related to smoking (\%) & 54.0 & 78.8 & 0.001 & 69.7 & 73.4 & 0.607 \\
\hline Awareness of blindness as related to smoking (\%) & 18.0 & 26.5 & 0.238 & 23.2 & 25.0 & 0.796 \\
\hline $\begin{array}{l}\text { Awareness of mouth and throat cancer as related to } \\
\text { smoking (\%) }\end{array}$ & 72.0 & 98.2 & $<0.001$ & 84.8 & 98.4 & 0.004 \\
\hline Awareness of lung cancer as related to smoking (\%) & 88.0 & 99.1 & 0.001 & 93.9 & 98.4 & 0.167 \\
\hline
\end{tabular}

the messages $(p=0.001)$, talk to others about warning labels $(\mathrm{p}<0.001)$, think about warning labels when they were not in sight $(\mathrm{p}<0.023)$ or were less likely to keep a warning label at home as a reminder $(\mathrm{p}=0.013$; online supplementary figure E2). No significant differences existed between COPD and non-COPD groups when comparing whether the warning labels were sufficient motivation to stop smoking ( $\mathrm{p}=0.240$; table 4$)$.

In terms of the age and sex of participants, females were more likely to experience fear when compared with males $(p=0.002)$, but not disgust or active avoidance of labels. They were also more likely to stop smoking following exposure $(p=0.002)$ and more likely to think about GHWL messages when they were not in sight $(\mathrm{p}=0.023)$. Those who experienced fear were younger $(\mathrm{p}=0.037)$, as were those who would actively avoid looking at labels $(p=0.008$; table 5$)$. Increased age was significantly correlated with a decrease in depth of processing of labels $(r=$ -0.386, $\mathrm{p}<0.001)$; older participants exhibited a decreased level of attention to detail when reading GHWL $(\mathrm{r}=-0.315, \mathrm{p}<0.001)$; they paid less attention to them $(\mathrm{r}=-0.351, \mathrm{p}<0.001)$; they were thinking less often about the labels $(\mathrm{r}=-0.375, \mathrm{p}<0.001)$, even when GHWL were not in sight $(\mathrm{r}=-0.201, \mathrm{p}<0.010)$, and they talked less about them $(\mathrm{r}=-0.31, \mathrm{p}<0.001$; table 6$)$.

The regression analysis to understand whether there were independent predictors of knowledge or awareness of smoking-related consequences revealed no significant association with the overall knowledge score of the respondent's age $(p=0.333)$, gender $(p=0.079)$, race $(\mathrm{p}=0.552)$ or smoking status $(\mathrm{p}=0.756)$.

\section{DISCUSSION}

Patients with COPD exhibit a decreased response to GHWL, an effect that can be referred to as desensitisation, whereas non-smokers and smokers without airway disease responded better. The use of GHWL evoked an emotional response of fear and disgust in the majority of participants, particularly in non-smokers, in females and in younger participants.

Table 3 Showing the number (\%) of each group that would hypothetically prevent or treat the named condition if they could choose only one from the given list

\begin{tabular}{|c|c|c|c|c|c|c|}
\hline & $\begin{array}{l}\text { COPD } \\
(n=50)\end{array}$ & $\begin{array}{l}\text { Non-COPD } \\
(n=113)\end{array}$ & $\begin{array}{l}\text { p } \\
\text { Value }\end{array}$ & $\begin{array}{l}\text { Smokers } \\
(n=99)\end{array}$ & $\begin{array}{l}\text { Non-smokers } \\
(n=64)\end{array}$ & p Value \\
\hline $\begin{array}{l}\text { If you could prevent or treat only one of heart disease, } \\
\text { stroke, blindness, mouth and throat cancer and lung } \\
\text { cancer, which would you choose? (\% choosing each } \\
\text { option) }\end{array}$ & $\begin{array}{l}\text { (Rank } \\
1-5)\end{array}$ & & & & & $\begin{array}{l}\text { (Overall } \\
\text { rank 1-5) }\end{array}$ \\
\hline Heart disease (\%) & $16.0(3)$ & $24.8(2)$ & 0.078 & $19.7(2)$ & $25.8(2)$ & $0.196(2)$ \\
\hline Stroke (\%) & $6.0(5)$ & $7.5(5)$ & 0.621 & $6.6(5)$ & $7.8(5)$ & $0.668(5)$ \\
\hline Blindness (\%) & $19.0(2)$ & $17.3(3)$ & 0.704 & $16.7(3)$ & $19.5(3)$ & $0.509(3)$ \\
\hline Mouth and throat cancer (\%) & $9.0(4)$ & $8.4(4)$ & 0.860 & $6.6(5)$ & $11.7(4)$ & $0.105(4)$ \\
\hline Lung cancer (\%) & $50.0(1)$ & $40.3(1)$ & 0.102 & $49.5(1)$ & $33.6(1)$ & $0.005(1)$ \\
\hline
\end{tabular}




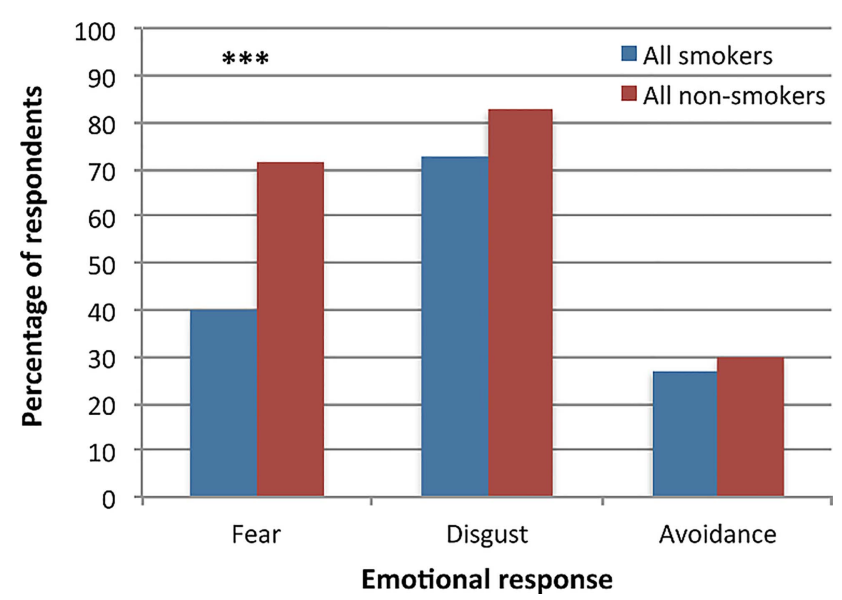

Figure 3 Emotional response to graphic health warning labels (GHWL; smokers vs non-smokers), showing the difference in respondents (\%) experiencing fear, disgust and avoidance after GHWL exposure. Statistically significant differences are marked $\left({ }^{* * *} p<0.001\right)$.

The effect of desensitisation can be defined as a process where repeated exposure results in habituation of a cognitive, emotional and physiological response. Psychological research has shown that novel events are processed more extensively than common events, ${ }^{35} 36$ and although some papers discuss desensitisation as a possible mechanism for a decreased impact of GHWL, ${ }^{37} 38$ it has largely been described in relation to graphic video game imagery and violence. ${ }^{39}$

\section{Awareness of smoking consequences and impact on future behaviour}

Various studies have outlined an increased awareness of smoking-related respiratory complications in patients with COPD. ${ }^{29} 34{ }^{40-43}$ In contrast, our study found that patients with COPD had a decreased awareness of

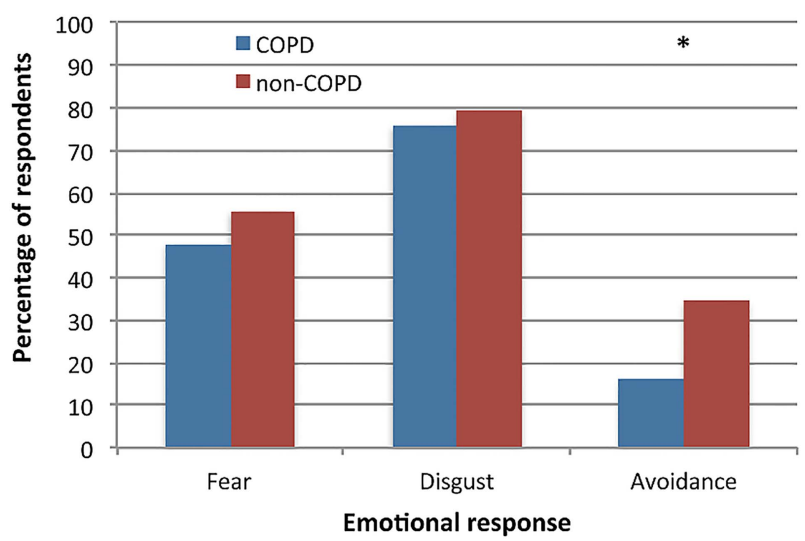

Figure 4 Emotional response to GHWL (COPD vs non-COPD), showing the difference in respondents (\%) experiencing fear, disgust and avoidance after GHWL exposure. Statistically significant differences are marked ( ${ }^{*} \mathrm{p}<0.05$; COPD, chronic obstructive pulmonary disease; GHWL, graphic health warning labels). consequences compared with patients without COPD and were less likely to quit if they developed any of the diseases; the same was true when smokers were compared with non-smokers. Smokers also scored significantly lower than non-smokers when asked how harmful smoking was to their health and they had a decreased awareness of mouth and throat cancer.

\section{The awareness of 'blindness' and its role in public health} campaigns

Blindness was the least well-known smoking-related risk despite all participants being highly motivated to prevent and treat it (ranked 2nd or 3rd in all groups, following lung cancer and heart disease). Up to $20 \%$ of new onset blindness in patients are attributed to smoking $^{44}$ and previous studies have found it more motivational than conventional messages in smoking prevention. ${ }^{18-20}$

Smoking-related lung cancer, heart disease, mouth and throat cancer and stroke are well recognised and publicised in printed media and TV advertising. ${ }^{34} 45$ This awareness is reflected across all study groups. However, it has been established that current smokers have a lower understanding of other risks including macular degeneration, cataracts and oral diseases compared with non-smokers. ${ }^{17} 1821$ In one study, less than $10 \%$ of patients older than 18 years were able to associate blindness with smoking. ${ }^{34}$

A study from Australia has shown an increased awareness of smoking-related eye disease due to public health strategies, ${ }^{46}$ and an increased emphasis on blindness in this context could have the potential to motivate and encourage smoking cessation. ${ }^{18}$

\section{Future implications}

GHWL appear to lose efficacy with increased exposure. Unfortunately, this limits the extensive use for the primary target groups, in particular long-term smokers and patients with COPD. A balance between the use of GHWL and the observed desensitisation effects needs to be considered. Therefore, specific health messages should be targeted at these cohorts over defined periods and reorganised with regular campaigns to avoid desensitisation. The knowledge that less well-known risks (eg, blindness) could have a similar impact as more well-known risks of smoking (eg, lung cancer and heart disease) provides the chance to alternate features of different diseases on GHWL in concerted public health campaigns.

Indeed, different approaches to promote smoking cessation are still required. Over the past few years it has been considered whether plain packages should be introduced, preventing the use of illusory packaging techniques as a means of attracting consumers. ${ }^{47}$ Evidence around plain packaging is currently based on indirect studies, ${ }^{4-52}$ and while Australia is the first country to sell tobacco products adopting this policy, ${ }^{53}$ the UK government, following consideration of such an approach, ${ }^{13}$ has currently rejected a proposal. 
Table 4 Emotional response and processing of GHWL, indicating the number of participants (\%) who responded with fear, disgust and avoidance and the number (\%) who were motivated to stop smoking

\begin{tabular}{|c|c|c|c|c|c|c|}
\hline Initial response to GHWL & $\begin{array}{l}\text { COPD } \\
(n=50)\end{array}$ & $\begin{array}{l}\text { Non-COPD } \\
(n=113)\end{array}$ & p Value & $\begin{array}{l}\text { Smokers } \\
(n=103)\end{array}$ & $\begin{array}{l}\text { Non-smokers } \\
(n=60)\end{array}$ & p Value \\
\hline ...Fear? (\%) & 48.0 & 55.8 & 0.360 & 39.8 & 71.9 & $<0.001$ \\
\hline ...Disgust? (\%) & 76.0 & 79.6 & 0.601 & 72.8 & 82.8 & 0.284 \\
\hline Ever avoided looking at GHWL? (\%) & 16.0 & 34.5 & 0.016 & 27.2 & 29.7 & 0.846 \\
\hline $\begin{array}{l}\text { Are the warning labels sufficient motivation for } \\
\text { you to stop smoking (if a current smoker) or not } \\
\text { start smoking (if a non-smoker or ex-smoker)? (\%) }\end{array}$ & 44.0 & 54.0 & 0.240 & 35.4 & 75.0 & $<0.001$ \\
\hline \multicolumn{7}{|l|}{ Processing of GHWL } \\
\hline \multicolumn{7}{|l|}{ Packaging processing response (1=never, 5=very often) } \\
\hline $\begin{array}{l}\text { (1) How carefully have you ever read the } \\
\text { warning messages on cigarette packaging? }\end{array}$ & $1.9(1.1)$ & $2.4(1.3)$ & 0.010 & $2.4(1.4)$ & $2.1(1.1)$ & 0.493 \\
\hline $\begin{array}{l}\text { (2) How often do you read the warning } \\
\text { messages on cigarette packaging? }\end{array}$ & $1.6(1.0)$ & $2.5(1.3)$ & $<0.001$ & $2.5(1.5)$ & $2.1(1.1)$ & 0.064 \\
\hline $\begin{array}{l}\text { (3) How often have you thought about the } \\
\text { warning messages on cigarette packaging? }\end{array}$ & $1.9(1.3)$ & $2.7(1.3)$ & 0.001 & $2.2(1.2)$ & $2.8(1.5)$ & 0.006 \\
\hline \multicolumn{7}{|l|}{ General processing response ( $1=$ never, $5=$ very often) } \\
\hline $\begin{array}{l}\text { (4) Have you ever talked to others about the } \\
\text { warning labels on cigarette packaging? }\end{array}$ & $1.5(1.1)$ & $2.5(1.4)$ & $<0.001$ & $1.8(1.1)$ & $2.7(1.5)$ & $<0.001$ \\
\hline $\begin{array}{l}\text { (5) How often have you thought about the } \\
\text { warning messages on cigarette packages } \\
\text { when there has been no pack in sight? }\end{array}$ & $1.5(0.9)$ & $1.9(1.2)$ & 0.023 & $1.6(1.0)$ & $2.0(1.3)$ & 0.112 \\
\hline $\begin{array}{l}\text { (6) How often have you kept a warning label } \\
\text { from a cigarette pack? }\end{array}$ & $1.0(0.3)$ & $1.4(1.0)$ & 0.013 & $1.2(0.8)$ & $1.3(0.8)$ & 0.995 \\
\hline
\end{tabular}

\section{Limitations}

The respondents in this study came from a hospital setting in respiratory and outpatient departments, and therefore a selection bias might have influenced some of the outcomes of our survey; the generalisability of our data should therefore be considered with caution. Several GHWL were shown to participants within a short time period and this could have caused a greater emotional response than showing single pictures.

Further, the COPD cohort tended to be older, with more male participants, whereas the non-smoker group consisted of proportionally more females. The numbers used in the analysis however, were taken from a reasonably large data set and represent consistent results among all groups, in line with previous findings. The smoking history was variable between patients in the COPD group as it included current smokers and also non-smokers. This could have impacted on and limited our results with regard to the COPD group (see online supplementary table E1).

Patients with COPD were more reluctant to take part in this survey and it is likely that a true aversion to GHWL might have been underestimated. In addition, although Hammond et $a l^{11}$ demonstrated that smoking cessation was related to high-cognitive processing of labels, intention to quit smoking was investigated here rather than actual behaviour change. Future research may need to investigate the achieved rate of smoking cessation following GHWL exposure and also the link between intention and actual change of smoking behaviour.

Table 5 Age and gender differences in the response to graphic health warning labels (GHWL), showing differences in gender (total number) and age (mean (SD)) in the emotional response to GHWL and motivation to stop smoking

\begin{tabular}{lllllll}
$\begin{array}{l}\text { Emotional response } \\
\text { to warning labels }\end{array}$ & Male-yes & Female-yes & $\chi^{2}$ & $\begin{array}{l}\text { Mean age } \\
\text { of those } \\
\text { who said 'yes' }\end{array}$ & $\begin{array}{l}\text { Mean age } \\
\text { of those } \\
\text { who said 'no' }\end{array}$ & $\begin{array}{l}\text { t Test } \\
\text { (two-tailed) }\end{array}$ \\
\hline Fear & $37 / 88$ & $50 / 75$ & 0.002 & $50.0(18.3)$ & $55.6(16.7)$ & 0.044 \\
Disgust & $66 / 88$ & $62 / 75$ & 0.235 & $51.3(17.4)$ & $57.1(18.7)$ & 0.112 \\
Avoidance & $21 / 88$ & $26 / 75$ & 0.129 & $47.0(16.1)$ & $54.8(18.0)$ & 0.008 \\
Sufficient to stop from smoking & $35 / 88$ & $48 / 75$ & 0.002 & $51.5(18.4)$ & $53.9(16.9)$ & 0.381 \\
\hline Statistically significant values are highlighted in grey.
\end{tabular}


Table 6 Age and gender differences in the processing of graphic health warning labels, showing Pearson's correlation with age and mean (SD) gender scores (1-10), in package processing ( 3 items) and general processing ( 3 items) of the warning labels

\begin{tabular}{|c|c|c|c|}
\hline & $\begin{array}{l}\text { Total package }(P) \text { processing } \\
\text { response }\end{array}$ & $\begin{array}{l}\text { Total general (G) processing } \\
\text { response }\end{array}$ & $\begin{array}{l}\text { Overall depth of } \\
\text { processing }(P+G)\end{array}$ \\
\hline Age $(r)$ & -0.393 & -0.276 & -0.386 \\
\hline p Value & $<0.001$ & $<0.001$ & $<0.001$ \\
\hline Mean score-male & $6.8(3.5)$ & $5.0(2.5)$ & $11.7(5.2)$ \\
\hline Mean score-female & $7.1(3.5)$ & $5.5(2.7)$ & $12.6(5.6)$ \\
\hline $\begin{array}{l}\text { Gender } t \text { test } p \text { value } \\
\text { (two tailed) }\end{array}$ & 0.559 & 0.217 & 0.323 \\
\hline \multicolumn{4}{|c|}{ Breakdown of package $(P)$ processing response } \\
\hline & Paid close attention & Thought about labels & Carefully read \\
\hline Age $(r)$ & -0.351 & -0.375 & -0.315 \\
\hline $\mathrm{p}$ Value & $<0.001$ & $<0.001$ & $<0.001$ \\
\hline Mean score - male & $2.2(1.3)$ & $2.3(1.3)$ & $2.2(1.3)$ \\
\hline Mean score -female & $2.3(1.3)$ & $2.6(1.4)$ & $2.2(1.2)$ \\
\hline $\begin{array}{l}\text { Gender t test } p \text { value } \\
\text { (two tailed) }\end{array}$ & 0.915 & 0.312 & 0.788 \\
\hline \multicolumn{4}{|c|}{ Breakdown of general (G) processing response } \\
\hline & Thought about when not in sight & Kept a label as a reminder & Talked to others about labels \\
\hline Age $(r)$ & -0.201 & -0.094 & -0.31 \\
\hline p Value & 0.010 & 0.232 & $<0.001$ \\
\hline Mean score-male & $1.6(1.0)$ & $1.3(0.9)$ & $2.1(1.3)$ \\
\hline Mean score-female & $2.0(1.3)$ & $1.2(0.8)$ & $2.3(1.4)$ \\
\hline $\begin{array}{l}\text { Gender } t \text { test } p \text { value } \\
\text { (two tailed) }\end{array}$ & 0.023 & 0.651 & 0.315 \\
\hline
\end{tabular}

Desensitisation is one explanation for our findings; however, it is possible that patients with COPD demonstrate an ambivalence towards risks to support their own self-esteem. ${ }^{55}$ This would reduce anxiety associated with a fear of the consequences of smoking ${ }^{56}$ and portray itself as a 'don't care' attitude. Leventhal ${ }^{57}$ postulated that fear messages may lead to two competing processes, either a 'danger control' or, in the case of our COPD cohort, a 'fear control' response. Indeed, where fearbased approaches have been used to reduce illicit drug rates, increased rates of drug abuse were described postintervention. ${ }^{58}$ Further qualitative work will help understand these specific responses better.

\section{CONCLUSION}

Prolonged exposure to GHWL may cause desensitisation, in particular to patients with COPD and current smokers. To maintain their efficacy, other strategies using the intermittent application of different features need to be employed within concerted health campaigns. Blindness has to be mentioned as a specific factor because it leads to a strong emotional response in the context of GHWL.

The evidence provided by our research is required to continue to develop successful public health campaigns, in particular because plain packaging has currently been rejected as a public health policy in the UK. These campaigns should focus on improving the lack of awareness of smoking-related diseases, especially in those with chronic smoking behaviour. Further, the timing of exposure to specific GHWL messages needs to be considered to avoid desensitisation. Future qualitative research is required to explore thoughts and beliefs of chronic smokers and patients with COPD, to understand any ambivalence towards smoking consequences and to investigate the underlying reasons. A more tailored approach will help to support effective primary and secondary prevention and smoking cessation interventions.

\section{Author affiliations}

'Lane Fox Respiratory Unit/Sleep Disorders Centre, Guy's \& St Thomas' NHS Foundation Trust, London, UK

${ }^{2}$ King's College London School of Medicine, London, UK

${ }^{3}$ Department of Public Health Sciences, King's College London \& NIHR Biomedical Research Centre, London, UK

Acknowledgements The authors gratefully acknowledge the help of Dr Boris Lams, Department of Respiratory Medicine, Guy's \& St Thomas' NHS Foundation Trust, London, UK in helping prepare ethical approval for this study. They are similarly grateful for the support of Dr Nicholas Hart, Department of Respiratory Medicine, Guy's \& St Thomas' NHS Foundation Trust, London, UK in undertaking the project and Dr Stewart Patterson, Division of Biomedical Sciences, King's College London, UK in facilitating the formation of the literature review, Dr Deborah Ng, Tan Tock Seng Hospital, Singapore for her help in the initial set-up of the study and advice, $\mathrm{Dr}$ Devanand Anantham, Department of Respiratory \& Critical Care Medicine, Singapore General Hospital for his aid in setting up and supervising the Singapore arm of the study and Professor John Moxham, Director of Strategy, King's Health Partners for his advice and guidance. Lastly, the authors are grateful to the team at the Lane Fox Respiratory Unit, Guy's \& St Thomas' NHS Foundation Trust, London, UK for allowing the facilitation of meetings and presentations surrounding the current project. 
Contributors CR designed the study, designed and adapted the data collection tools, set up the research teams in Singapore (Singapore arm, data not yet available) and London, obtained the ethical approval, monitored the data collection and data collection training, collected data, revised and oversaw the formation of the literature review, analysed data and wrote and revised the literature review, analysis and discussion sections of the paper. $\mathrm{He}$ is the first guarantor. BC collected data, made significant contribution to the analysis and wrote proportions of the analysis and discussion sections. PD made significant contribution to data collection and review of the paper. SS performed initial literature search and literature review. BS collected data and aided in elements of the data analysis section. MB made significant contribution to the data collection and review of the paper. $A D$ was vital in the statistical analysis, analysis section and also tailoring of the discussion section. JS is the second guarantor. He oversaw data collection in the London arm, established, enabled and supervised the undertaking of the project in the London site; facilitated the formation of the London research team; safeguarded the data collected and was responsible for overlooking, guiding and redrafting the eventual manuscript prior to submission.

Funding This research was supported by the National Institute for Health Research (NIHR) Biomedical Research Centre at Guy's and St Thomas' NHS Foundation Trust and King's College London.

Competing interests None.

Ethics approval Sunderland Research Ethics Committee-12/NE/0013.

Provenance and peer review Not commissioned; externally peer reviewed.

Data sharing statement Extra data are available on emailing the corresponding author (c.ratneswaran@gmail.com). This includes the raw data collected if necessary and is available to researchers looking to further investigate the scope of the current project.

Open Access This is an Open Access article distributed in accordance with the Creative Commons Attribution Non Commercial (CC BY-NC 3.0) license, which permits others to distribute, remix, adapt, build upon this work noncommercially, and license their derivative works on different terms, provided the original work is properly cited and the use is non-commercial. See: http:// creativecommons.org/licenses/by-nc/3.0/

\section{REFERENCES}

1. Alwan A. Global status report on noncommunicable diseases 2010. Geneva: World Health Organization, 2011.

2. Peto R, Darby $\mathrm{S}$, Deo $\mathrm{H}$, et al. Smoking, smoking cessation, and lung cancer in the UK since 1950: combination of national statistics with two case-control studies. BMJ 2000;321:323-9.

3. Lopez AD, Mathers CD, Ezzati M, et al. Global burden of disease and risk factors. J Nutr 2006;136:2945-51.

4. Forey BA, Thornton AJ, Lee PN. Systematic review with meta-analysis of the epidemiological evidence relating smoking to COPD, chronic bronchitis and emphysema. BMC Pulm Med 2011;11:36

5. Coronini-Cronberg S, Heffernan C, Robinson M. Effective smoking cessation interventions for COPD patients: a review of the evidence. JRSM Short Rep 2011;2:78.

6. West R. Smoking cessation interventions. In: Britton J, ed. Fifty years since smoking and health: progress, lessons and priorities for a smoke-free UK, UK: Royal College of Physicians, 2012:27-31.

7. Hammond D. Health warning messages on tobacco products: a review. Tob Control 2011;20:327-37.

8. Vardavas $\mathrm{Cl}$, Connolly G, Karamanolis $\mathrm{K}$, et al. Adolescents perceived effectiveness of the proposed European graphic tobacco warning labels. Eur J Public Health 2009;19:212-17.

9. Hammond D, Fong GT, McNeill A, et al. Effectiveness of cigarette warning labels in informing smokers about the risks of smoking: findings from the International Tobacco Control (ITC) Four Country Survey. Tob Control 2006;15(Suppl 3):iii19-25.

10. Fong GT, Hammond D, Jiang $Y$, et al. Perceptions of tobacco health warnings in China compared with picture and text-only health warnings from other countries: an experimental study. Tob Control 2010;19(Suppl 2):i69-77.

11. Hammond D, Fong GT, McDonald PW, et al. Impact of the graphic Canadian warning labels on adult smoking behaviour. Tob Control 2003;12:391-5

12. Sobani Z, Nizami S, Raza E, et al. Graphic tobacco health warnings: which genre to choose? Int J Tuberc Lung Dis 2010;14:356-61.
13. UK Department of Health. Healthy lives, healthy people: a tobacco control plan for England. London: UK Government, 2011.

14. Britton J. Summary and conclusions: smoking and health in the next fifty years. In Britton J. ed. Fifty years since smoking and health: progress, lessons and priorities for a smoke-free UK. Royal College of Physicians, 2012:52-4.

15. Oncken C, McKee S, Krishnan-Sarin S, et al. Knowledge and perceived risk of smoking-related conditions: a survey of cigarette smokers. Prev Med 2005;40:779-84.

16. Raupach T, Shahab L, Baetzing S, et al. Medical students lack basic knowledge about smoking: findings from two European medical schools. Nicotine Tob Res 2009;11:92-8.

17. Al-Shammari KF, Moussa MA, Al-Ansari JM, et al. Dental patient awareness of smoking effects on oral health: comparison of smokers and non-smokers. J Dent 2006;34:173-8.

18. Handa S, Woo JH, Wagle AM, et al. Awareness of blindness and other smoking-related diseases and its impact on motivation for smoking cessation in eye patients. Eye 2011;25:1170-6.

19. Moradi P, Thornton J, Edwards R, et al. Teenagers' perceptions of blindness related to smoking: a novel message to a vulnerable group. Br J Ophthalmol 2007;91:605-7.

20. $\mathrm{Ng} \mathrm{DH}$, Roxburgh ST, Sanjay S, et al. Awareness of smoking risks and attitudes towards graphic health warning labels on cigarette packs: a cross-cultural study of two populations in Singapore and Scotland. Eye 2010;24:864-8.

21. Lung ZH, Kelleher MG, Porter RW, et al. Poor patient awareness of the relationship between smoking and periodontal diseases. Br Dent J 2005:199:731-7.

22. Bava S, Tapert SF. Adolescent brain development and the risk for alcohol and other drug problems. Neuropsychol Rev 2010;20:398-413.

23. Kviz FJ, Clark MA, Crittenden KS, et al. Age and readiness to quit smoking. Prev Med 1994;23:211-22.

24. Stoller EP. Interpretations of symptoms by older people: a health diary study of illness behavior. J Aging Health 1993;5:58-81.

25. Walters N, Coleman T. Comparison of the smoking behaviour and attitudes of smokers who attribute respiratory symptoms to smoking with those who do not. Br J Gen Pract 2002;52:132.

26. Fritzsche $\mathrm{A}$, Watz $\mathrm{H}$, Magnussen $\mathrm{H}$, et al. Cognitive biases in patients with chronic obstructive pulmonary disease and depression-a pilot study. Br J Health Psychol 2013;18:827-43.

27. Rusanen M, Ngandu T, Laatikainen T, et al. Chronic obstructive pulmonary disease and asthma and the risk of mild cognitive impairment and dementia: a population based CAIDE study. Curr Alzheimer Res 2013;10:549-55.

28. Singh B, Parsaik AK, Mielke MM, et al. Chronic obstructive pulmonary disease and association with mild cognitive impairment: the Mayo Clinic Study of Aging. in Mayo Clinic Proceedings. Elsevier, 2013.

29. Hoth KF, Wamboldt FS, Bowler R, et al. Attributions about cause of illness in chronic obstructive pulmonary disease. J Psychosom Res 2011;70:465-72.

30. Warnakulasuriya S. Global epidemiology of oral and oropharyngeal cancer. Oral Oncol 2009;45:309-16.

31. Hecht SS. Tobacco smoke carcinogens and lung cancer. J Natl Cancer Inst 1999;91:1194-210.

32. Isles CG, Hole DJ, Hawthorne VM, et al. Relation between coronary risk and coronary mortality in women of the Renfrew and Paisley survey: comparison with men. Lancet 1992;339:702-6.

33. Shinton R, Beevers G. Meta-analysis of relation between cigarette smoking and stroke. BMJ 1989;298:789.

34. Bidwell G, Sahu A, Edwards R, et al. Perceptions of blindness related to smoking: a hospital-based cross-sectional study. Eye 2005;19:945-8.

35. Tversky A, Kahneman D. Availability: a heuristic for judging frequency and probability. Cognit Psychol 1973;5:207-32.

36. Wyer RS Jr, Hartwick J. The role of information retrieval and conditional inference processes in belief formation and change. Adv Exp Soc Psychol 1980;13:241-84.

37. Veer E, Rank T. Warning! The following packet contains shocking images: the impact of mortality salience on the effectiveness of graphic cigarette warning labels. J Consum Behav 2012;11:225-33.

38. Dieterich SE. Graphic cigarette package warning labels: investigating the effectiveness of graphic images among new and occasional smokers. Colorado State University, 2012.

39. Engelhardt CR, Bartholow BD, Kerr GT, et al. This is your brain on violent video games: neural desensitization to violence predicts increased aggression following violent video game exposure. J Exp Soc Psychol 2011;47:1033-6.

40. Gorecka D, Bednarek M, Kislo A, et al. [Awareness of airflow obstruction together with antismoking advice increases success in cessation smoking]. Pneumonol Alergol Pol 2000;69:617-25. 
41. Bednarek M, Gorecka D, Wielgomas J, et al. Smokers with airway obstruction are more likely to quit smoking. Thorax 2006;61:869-73.

42. Laniado-Laborín R. Smoking and chronic obstructive pulmonary disease (COPD). Parallel epidemics of the 21st century. Int $J$ Environ Res Public Health 2009;6:209-24.

43. Kotz D, Vos R, Huibers MJH. Ethical analysis of the justifiability of labelling with COPD for smoking cessation. $J$ Med Ethics 2009;35:534-40.

44. Mitchell P, Chapman S, Smith W. Smoking is a major cause of blindness. Med J Aust 1999;171:173.

45. Shahab L, Jarvis MJ, Britton J, et al. Prevalence, diagnosis and relation to tobacco dependence of chronic obstructive pulmonary disease in a nationally representative population sample. Thorax 2006;61:1043-7.

46. AMD Alliance International. Awareness of age-related macular degeneration and associated risk factors, AMD Global Report 2005. Toronto: AMD Alliance International, 2005

47. Cunningham R. Gruesome photos on cigarette packages reduce tobacco use. Bull World Health Organ 2009;87:569.

48. Goldberg ME, Kindra G, Lefebvre J, et al. When packages can't speak: possible impacts of plain and generic packaging of tobacco products. RJ Reynolds, 1995;521716345:6771.

49. Hoek J, Wong C, Gendall P, et al. Effects of dissuasive packaging on young adult smokers. Tob Control 2011;20: $183-8$.
50. Moodie C, Mackintosh AM, Hastings G, et al. Young adult smokers' perceptions of plain packaging: a pilot naturalistic study. Tob Control 2011;20:367-73.

51. Thrasher JF, Rousu MC, Hammond D, et al. Estimating the impact of pictorial health warnings and "plain" cigarette packaging: evidence from experimental auctions among adult smokers in the United States. Health Policy 2011;102:41-8.

52. Wakefield MA, Germain D, Durkin SJ, How does increasingly plainer cigarette packaging influence adult smokers' perceptions about brand image? An experimental study. Tob Control 2008;17:416-21.

53. Australian Government. Tobacco Plain Packaging Act 2011: an Act to discourage the use of tobacco products, and for related purposes. Canberra: Australian Government, 2011.

54. Australian Government. Tobacco Plain Packaging Amendment Regulation 2012 (No 1). Canberra: Australian Government, 2012.

55. Arndt J, Schimel J, Goldenberg JL. Death can be good for your health: fitness intentions as a proximal and distal defense against mortality salience1. J Appl Soc Psychol 2003;33:1726-46.

56. Greenberg J, Solomon S, Pyszczynski T. Terror management theory of self-esteem and cultural worldviews: empirical assessments and conceptual refinements. Academic Press, 1997.

57. Leventhal $\mathrm{H}$. Findings and theory in the study of fear communications. Adv Exp Social Psychol 1970;5:119-86.

58. Hornik R, Jacobsohn L, Orwin R, et al. Effects of the national youth anti-drug media campaign on youths. Am J Public Health 2008;98:2229. 